\title{
Educating Adults with an Augmented Reality Game: A Content Analysis Approach
}

\author{
Konstantina Sdravopoulou ${ }^{1}$, Juan Manuel Muñoz González² and María Dolores Hidalgo-Ariza ${ }^{3}$
}

1 Department of Education, University of Cordoba sdravopouloukon@gmail.com
2 Department of Education, University of Cordoba juan.manuel@uco.es
3 Department of Education, University of Cordoba lola.hidalgo@uco.es
* Correspondence: $\underline{\text { sdravopouloukon@gmail.com }}$

\begin{abstract}
With the exception of Pokémon Go, relatively little is known about other Mobile Augmented Reality (MAR) games, and the attitudes of middle-aged and elderly adults towards them are hitherto poorly examined. The aim of this research is to examine opinions of young, middle-aged and elderly adults about the location-based MAR game Ingress. The responses to questions related to Ingress were collected from 24 adult players aged 20-60 from Greece and subsequently were analyzed by means of content analysis, both qualitatively and quantitatively, using the Jaccard index of similarity. Our findings show that opinions of young people (20-35) agree more with those of elderly adults (52>) than with those of the intermediate age group of 36-51. It was also revealed that the knowledge of geography facilitates to play the game better, the game's scenario is very interesting to adults and the feeling of playing locally in a global game is also appreciated by all age groups. Besides these, with this research it is shown that a) content analysis is a valuable method for exploring opinions and attitudes of adult users towards MAR games and b) Jaccard indices can be used to quantitatively explore themes emerging from content analysis.
\end{abstract}

Keywords: Mobile Augmented Reality (MAR), Augmented Reality, Adult Education, MAR Games, Content Analysis, Jaccard index, Ingress, Augmented Reality in Education

\section{Introduction}

Innovations using mobile technologies have expanded into all market categories over the past few years [1,2] and augmented reality (AR) applications for mobile devices have dynamically entered the consumer market [3]. In addition, innovations have converged from devices used for personal tasks (e.g. a mobile phone can be used to make phone calls and to serve as a digital assistant) to devices that can be used for a broad range of tasks [4].

$\mathrm{AR}$ is the name of a media type in which digital knowledge is realistically incorporated into the physical world, merges the physical and virtual worlds together and offers opportunities for different sectors, including those that make entertaining and engaging games [5]. Unlike virtual reality, AR is not cut off from reality, but, following Craig [6], it is a "medium in which digital information is superimposed on the physical world that is interactive in time and in both spatial and temporal registration with the physical world". 
In the past five years, research interest in AR has increased, with researchers focusing on user adoption behaviour [7], marketing potential [8] and user requirements [8,9]. In general, these studies suggest that new and diverse factors drive consumer behaviour (e.g., wearability, perceived increase), so that user behaviour can not be explained by single hypotheses, since different factors drive different patterns of usage.

Previous studies on Computer-Mediated Environments (CME) have shown that flow, quality of service and satisfaction have a direct or indirect effect on the intention to continue use. Since people play games to experience the sense of flow and this aspect has a strong effect on the willingness of a consumer to play a mobile game [10] and as a consequence this study therefore examines flow-related variables first.

Probably, the most extensively studied Mobile Augmented Reality (MAR) game is Pokémon Go. Schade et al. [11] evaluated the influence of playing Pokémon Go on the physical activity of students and found that the amount of steps or distances travelled by university students did not increase. Madrigal-Pana et al. [12] examined the perception of videogames and the use of Pokémon Go in Costa Rica and identified positive and negative perceptions of videogames mediated by age and level of education and that attitudes towards videogame playing depended on age and gender. Ma et al. [13] analyzed the relationship between the use of Pokémon Go and the physical activity of players and how the relationship varies between players with distinct levels of physical activity. Finco et al. [14] studied how Pokémon Go allows people to walk in various urban places, encouraging users to be more involved and connect with other users, and discovered that it is one of the first mobile-based gameplays that can promote a healthy lifestyle with a new way of communicating, while transforming sedentary habits with a wide potential for health education.

But this game is mainly intended for youngsters and, as a matter of fact, most of the research carried out in $\mathrm{AR}$ in education has focused on how younger generations perceive and evaluate such applications, but there is a marked deficit in scientific research concerning the use of AR by adult learners.

As well documented, adult learning differs from that of minors in seven key respects, according to Courau [15], which can be summarized briefly as follows: i) adult learning is encouraged when instruction is specifically linked to the everyday life of an adult; ii) if it is not followed by complete comprehension, adult learning becomes difficult; iii) recognition of the aims of the educational project is significant for an adult learner; iv) adult learners are directly interested in the instruction and the objects of learning, that is they learn actively; v) adults learn easier if they think they contribute towards a good cause or within the context of a community of learners. However, apart from the above, it should be noticed that adults have a wide variety of types of learners and thus, while minors engage in an educational process because they owe it to the state or their parents, adults learn and/or participate in an educational program for different reasons also (i.e. to use the knowledge and skills they will acquire either in their career or in their social advancement, to improve their financial situation, etc).

Consequently, adult education and training may follow the implementation of a mixture of learning theories. For instance, environment-focused learning theories place great emphasis on the environment, from which the stimuli that contribute to the learning process come, as well as human contacts and interactions between the person and the environment, eventually contributing to the transformation of learning into action. Also, by the theory of "personal creation" [16], adult learning is not decided by external processes, but the learner is the creator of his own learning and information.

Newly emerging, location-based AR games for mobile games need more exploration. Also, mobile AR games are usually based on a "freemium" pricing model, meaning that the game is free to download and play, while users can purchase premium features [17] and most concepts and ideas related to adult education have not been extended to learning AR. Although the mobile gaming industry is rapidly growing and competitive and since previous studies 
have already focused on Pokémon Go [18, 12, 13, 14], other location-based AR mobile games deserve investigation as well. For these reasons, this study focuses on evaluating the location-based AR game "Ingress" to identify what players enjoy about the game, what they dislike, and what changes they would suggest to be made to it.

"Ingress" was developed and published in 2014 by Niantic, a Google spinoff company (the same company that created Pokémon Go) which announced it had more than 7 million players in 2015. As a basis for overlaying game elements to real-world places, the game uses Google Maps. There are two factions in Ingress ("Enlightened" vs. "Resistance") that players need to choose from to identify themselves with. The main objective of the game is to take control of "portals" that are mapped to different locations in the real world, such as landmarks, public places, parks or local businesses [19]. By putting a mark (called "resonator") at a portal users mark the portal based on their team membership and in this way the portal is captured by the user (on behalf of her team) and the portal changes colour to either green for the faction of "Enlightened" ones or blue for the faction of the "Resistance". If players come across portals already run by the opposite team, by using in-game weapons such as "bursters" or "ultra-strikes", they can disable the influence of the opposing faction. By deploying "fields" connecting three portals into a triangle, players aim to take control of as many portals as possible and control a geographical area as large as possible. These game control activities can occur at different scales; "microfielding" is called the activity of connecting portals highly concentrated in a small local region, while a large-scale activity that can span several states or even countries is called a "megafield". Many participants and tight coordination are both needed for the bigger fielding efforts and are referred to as "field operations" ("field ops"). Eventually, the main objective of the game is to conquer as many portals as possible on behalf of a faction and to impose control over a large field in order to obtain "Mind Units".

One of the key features of adult learning is that adults need to connect learning with previous experiences and also need to express their own opinions about what they learn. Considering this, and in view of the deficit in the literature related to how adults learn to play location-based MAR games, this research tackles the following questions: i) How to assess adult learning of Ingress? ii) What are the main adults' attitudes and opinions about Ingress? and iii) How do these opinions depend on user age?

\section{Materials and Methods}

To achieve the aim and objectives of the project, qualitative research methods were applied for data collection in order to assess the educational activity that was carried out centered around the location-based MAR game Ingress. The survey questionnaire was composed of open questions, and was developed specifically for this work. The questions are the following:

Q1: How much does knowing the geography of the area facilitate you play the game better?

$\mathrm{Q}_{2}$ : What is your opinion about the scenario of the game?

Q3: What is the feeling of playing locally in a global game?

Q4: Are there any idle phases during the game (intervals of repetitions or dullness) and what is the likely cause of those idle phases?

Q5: What changes would you make to the game with respect to shapes, colors, ordering and/or sequencing of forms, sounds, texts?

These questions allow for the understanding of how the experience of playing Ingress fits into players' lives. The open questions focused more on experience and mood, asking what players enjoy about the game, what they dislike, and what changes they suggest. These questions were phrased in a neutral manner, to allow both positive and negative experiences to be shared. In the present case, interviews were appropriate as a qualitative method [20] and the data obtained from the qualitative research were examined in detail by means of methods of "content analysis". 
The survey involved 24 users in Greece, aged 20 to 60 years old. The participants were chosen based on four characteristics: a) they have been using an Android smartphone, b) they understand written and spoken English, c) they can understand the directions that the game provides them (either written or orally) and d) they are not familiar with Ingress at all. Of the participants, 20.8\% were graduates of secondary education, $8.4 \%$ University students, 33.3\% University graduates, 33.3\% hold a master's degree and 4.2\% hold a doctoral degree.

The participants were trained to learn the basics of Ingress for two hours. Their responses were analysed following methods of content analysis, which is "a research technique for making replicable and valid inferences from texts (or other meaningful matter) to the contexts of their use" [21]. Content analysis as a method necessitates the use of advanced techniques and is independent of the researcher's personal authority [21].

Six steps are usually used in content analyses to describe the procedure:

i) Unitizing: the process of systematically separating text segments that are relevant to the main focus of the study.

ii) Sampling: by restricting observations to a manageable subset of units that is statistically or conceptually representative of the set of all possible units, sampling helps the analyst to save time or other resources.

iii) Coding: the process of converting information into code; the process of defining or classifying recording units according to the categories of the chosen analytical constructs. In this phase, main themes and subthemes are identified from within the responses.

iv) Data reduction: This step meets the needs of analysts who need efficient representations of large amounts of data.

v) Inferring conclusions: In a content analysis, this stage employs an understanding of how the variable accounts of coded data relate to the phenomena the researcher is interested in learning about.

vi) Narrating: the researchers make their findings understandable to others by narrating the responses to content analysts' questions.

The 24 participants of this research were evenly distributed per age group: three age groups were defined with 8 persons in each group and at 15 years' intervals: 20-35, 36-51, 52-67. The means and the standard deviations per age group are given in table 1.

Table 1. Age groups with number of participants per group, mean age and standard deviation.

\begin{tabular}{|l|l|l|l|}
\hline & Participants & $\begin{array}{l}\text { Mean } \\
\text { age }\end{array}$ & $\begin{array}{l}\text { Standard } \\
\text { deviation }\end{array}$ \\
\hline $20-35$ & 8 & 28.6 & 5.55 \\
\hline $36-51$ & 8 & 45.9 & 4.94 \\
\hline $52+$ & 8 & 56.6 & 1.92 \\
\hline
\end{tabular}

Content analysis was performed on the users' responses both qualitatively (to identify characteristic sentences expressing attitudes and opinions about it) and quantitatively. For the quantitative assessment of similarities of responses per question and per subtheme, the Jaccard similarity index $J_{i j}$ was calculated pairwise, for every pair $i$, $j$ of participants [22]: 


$$
J_{i j}=\frac{M_{11}}{M_{01}+M_{10}+M_{11}}
$$

where $M_{11}$ denotes the number of agreements between respondents on a subtheme ("yes-yes"), $M_{01}$ the number of disagreements where the respondent $i$ responded "no" and the $j$ "yes" and Miothe number of times with the reverse responses. Although originating from ecology [23], the index has found applications in many domains, including content analysis $[24,25,26,27,28,29]$.

After the creation of the $24 \times 24$ matrix of Jaccard indexes for all the 24 participants of this research showing agreement or disagreement among participants per subtheme, the mean Jaccard index by pair of participants $i, j$, for all $n$ raters can then be calculated from the following formula:

$$
\hat{J}_{i j}=\frac{2}{n(n-1)}\left[\sum_{i=1}^{n} \sum_{j=1}^{n} J_{i j}\right]
$$

Consequently, the inter-age group Jaccard index $J_{u, v}$ for age groups $u, v$ (with $u=1,2,3$ and $v=1,2,3$ ) is calculated and hence the sum of values of the similarity indexes for all subthemes of each question and for all participants, by age group:

$$
J_{u, v}=\sum_{u, v}\left(J_{i j}\right)_{u, v}
$$

for all age groups (three in this case), while the mean Jaccard similarity index for each question and age group, taking into account all subthemes and among all participants by age group is:

$$
\hat{J_{u, v}}=\frac{\sum_{u, v}\left(J_{i j}\right)_{u, v}}{\hat{J}_{i j}}
$$

Consequently, chi-square test was performed to test the significance of the entries of the resulting matrices for each and all questions.

\section{Results}

The results concern the fields examined: the role of geography in playing the game better, the scenario of the game, the feeling of playing locally in a global game, the role of the idle phases and the suggestions for improvement of the game.

\section{i) Knowing of geography facilitates the game}

When asked if the knowledge of the geography of the participants' area helped them to play the game better, the vast majority of participants answered in the affirmative for reasons such as that in an unknown area they would face additional difficulty, that they save time, enjoy it more, feel safe. 
The thematic "knowing the geography facilitates you play the game better" is found related with 13 subthemes; the following: it is decidedly a game based on geography, it gives motive to continue playing, unknown areas are associated with more difficulty, knowledge of the area helps to gain time, the game has suspense, there are texts with information about the local area, the game can be enjoyable, it gives a sense of safety, requires concentration, can be indifferent, is based on walking, an experiential knowledge of geography helps play it better, it motivates to know other areas (figure 1).

As many as twelve subthemes were evaluated positively and one negatively and 50\% of the adult learners agreed that Ingress is a game based on geography and that by knowing the area they save time. The mean similarity of responses between the participants was calculated with the Jaccard similarity index which is 0,11 for this question.

Quoting two characteristic responses:

"It is not possible to play Ingress if you do not know the geography of the area that plays it very well. It is a geographical game combined with augmented reality. This is because either you will play (so it presupposes knowing where you are going without wasting time), or you will be looking to find the portals (so you are not playing but you are looking for and learning the area)".

"The fact that I am unfamiliar with the area discourages me so much that I want to play it less than once or twice a month. I do not like searching areas, either with Ingress or without it. If I were in the city where I was born and raised, I would play it every day. That is, for a game like Ingress, knowing the area you are playing in is a determining factor that can function either very positively or very negatively".

Analyzing the subthemes, it was revealed that the subtheme "game based on geography" was highlighted more by the age group 36-51 (with a percentage of 67\%), followed by the age group 20-35 (with a percentage of 22\%) and by the age group 52> with a percentage of $9 \%$. Interestingly, those who expressed the opinion that knowledge of the area's geography did not help them play the game any better, mentioned as a reason that Ingress is based on movement and therefore it is unavoidable to move into unknown areas also. 


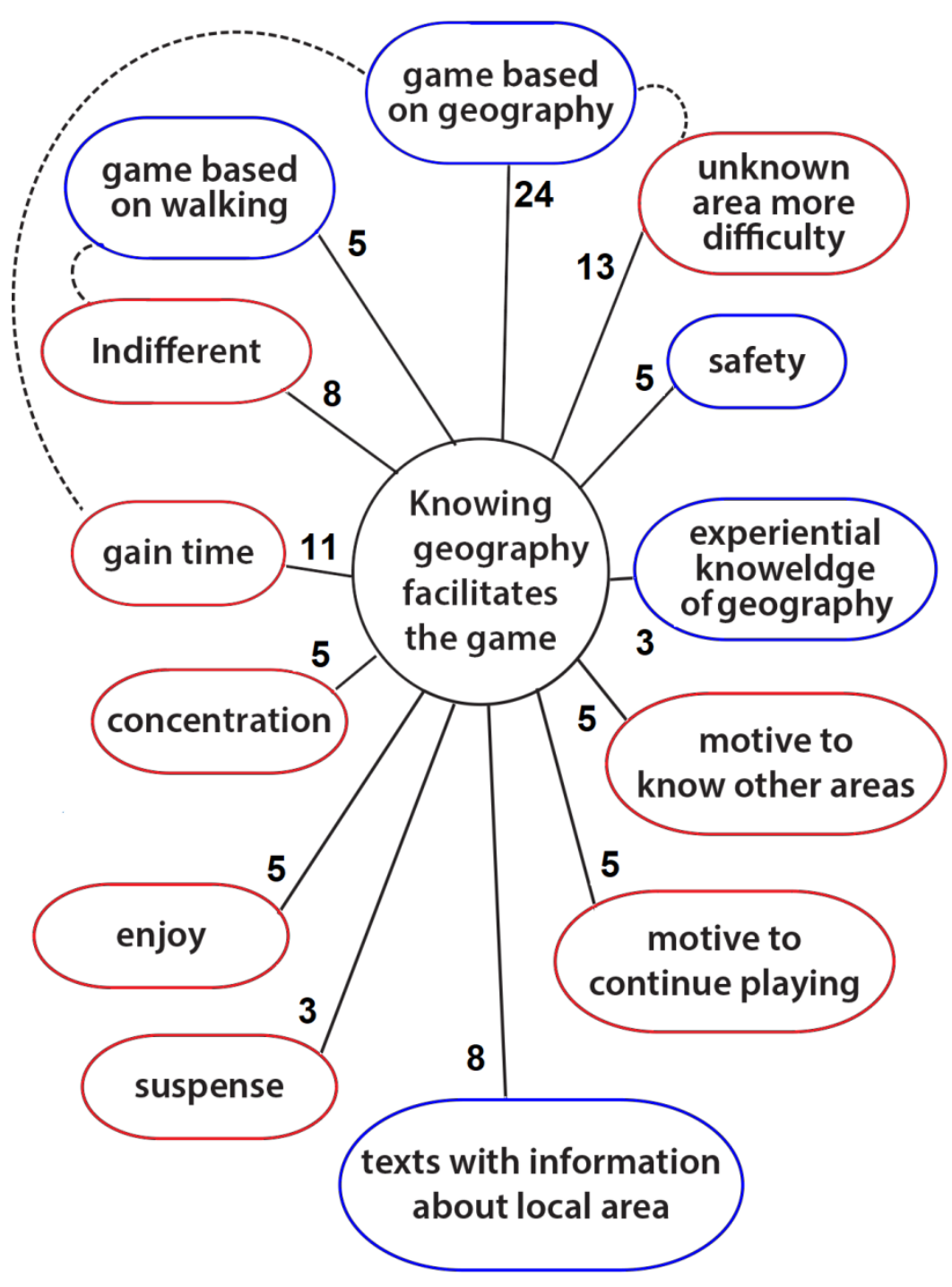

Figure 1. Subthemes resulting from the content analysis of the responses to question 1. Percentages correspond to the number of mentions related to the main thematic "knowing geography facilitates the game". Some subthemes were mentioned more than once by the participants who mentioned also the subthemes that are connected with dotted links. Subthemes with red color relate the user, while those with blue color relate to the game.

\section{ii) Scenario of the game}

Opinions varied regarding the Ingress scenario. The content analysis showed that the central thematic ("scenario of the game") is related to 12 subthemes (figure 2), indicating that it is fascinating to be part of a group, the scenario is giving suspense to the user while it may also appear indifferent, relates to an interesting discussion about the evolution of humanity, allows the identification with one of the groups and for communication among team members, is addressed to all ages, the game's oral instructions give more information about it, it is challenging, reminiscent of fairy tales or conspiracy theories and that it is interesting as it refers to CERN. 
As many as $41 \%$ of the answers indicated that the scenario of the game interestingly reflects part of the discussion about the evolution of humanity, while with equal percentages $(10.3 \%)$ follow the opinions that the game allows communication between the team members as well as the opinion that it is indifferent.

Among the opinions expressed, the following two are perhaps more characteristic:

"It's perfect. First of all, it has an interesting scenario, while I expected it to be monotonous. You are member of a team and you are called to defend your team's interests, you make friends and allies; you are not alone. Each area is marked either by your own team or by the opponents and you need help to advance the game. You do not know what will happen next and you also have a purpose for which you are fighting for; a mission".

"I liked the script. It also has to do with conversations. I hear so much about technology; to what extent have new technologies changed our lives and since the human species is evolving, such or a similar evolution is inevitable. And on this issue there are various views, theories".

In fact, the subtheme "discussion about the evolution of humanity" concentrated as many as $58 \%$ of the mentions of the age group 36-51, followed by the age group 20-35 with 25\% and finally the age group 52> with $17 \%$. The mean similarity of the responses between the participants was calculated with the Jaccard similarity index which is 0,212 .

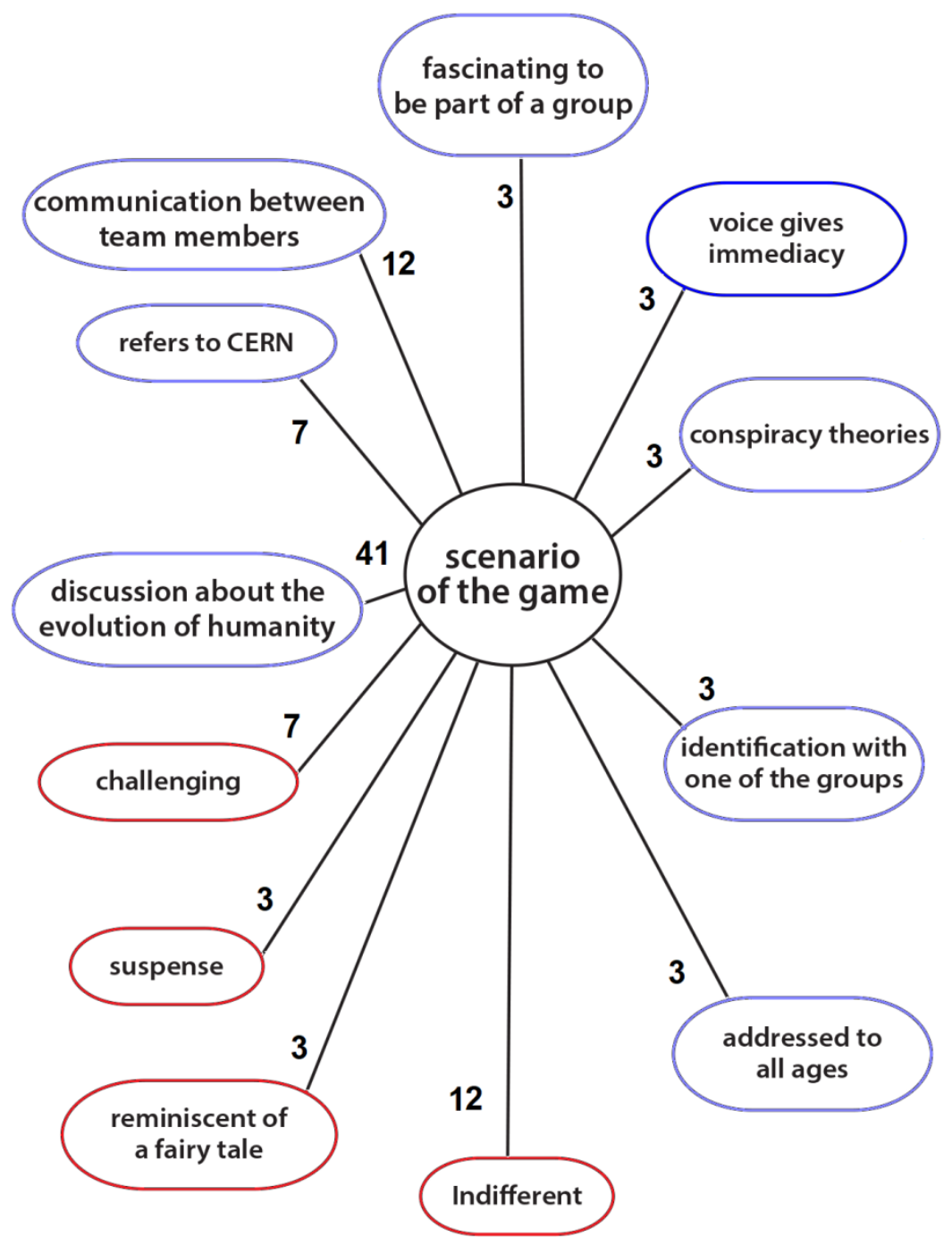


Figure 2. Subthemes with percentages of mentions related to the main thematic "scenario of the game" (question 2). Subthemes with red color relate to the user, with purple relate to society and blue relate to the game.

\section{iii) Feeling of playing locally in a global game}

When asked about how participants feel about by playing locally in a world game, feelings of excitement, insecurity and caution were reported. It was also pointed out that the game is relevant to most of them and indeed, for some participants it was the only game they knew by which it is possible to play from one's own country at a global scale.

Specifically, the content analysis of the responses to question 3 showed that the thematic "the feeling of playing locally in a global game" is related to 6 subthemes (figure 3): excitement, current, game played worldwide, hesitation, insecurity, has advantages and disadvantages.

Two indicative responses are:

"This side of the game is also relevant. We now live in a globalized society, whether we realize it or not. Some of us (realize it) to a higher degree. As for me, it is a daily experience to meet people from different countries, because I am doing my master's degree in England and in my department my fellow students are from 11 different countries".

"It is good to be accustomed to thinking locally but also through a global context. Because we are used to thinking only locally and without being part of a broader plan and of course without a specific ideology. On the other hand, for me personally, I felt it was very binding that in order to be able to play the game, I had to choose one of the two warring factions".

Of the six subthemes, three are evaluated positively, two negatively and one neutral. The mean similarity of the responses between the participants was calculated with the Jaccard similarity index which is 0,279 . The subtheme "timely" concentrated $42 \%$ of the mentions. Next is "excitement" with $22.5 \%$ of mentions, therefore these two subthemes totaling for over $50 \%$ of mentions. The subtheme "timely" focused more on the age group 20-35 with a percentage of $46 \%$, then the age group 52> with a percentage of $31 \%$ and finally the age group $36-51$ with a percentage of $23 \%$. 


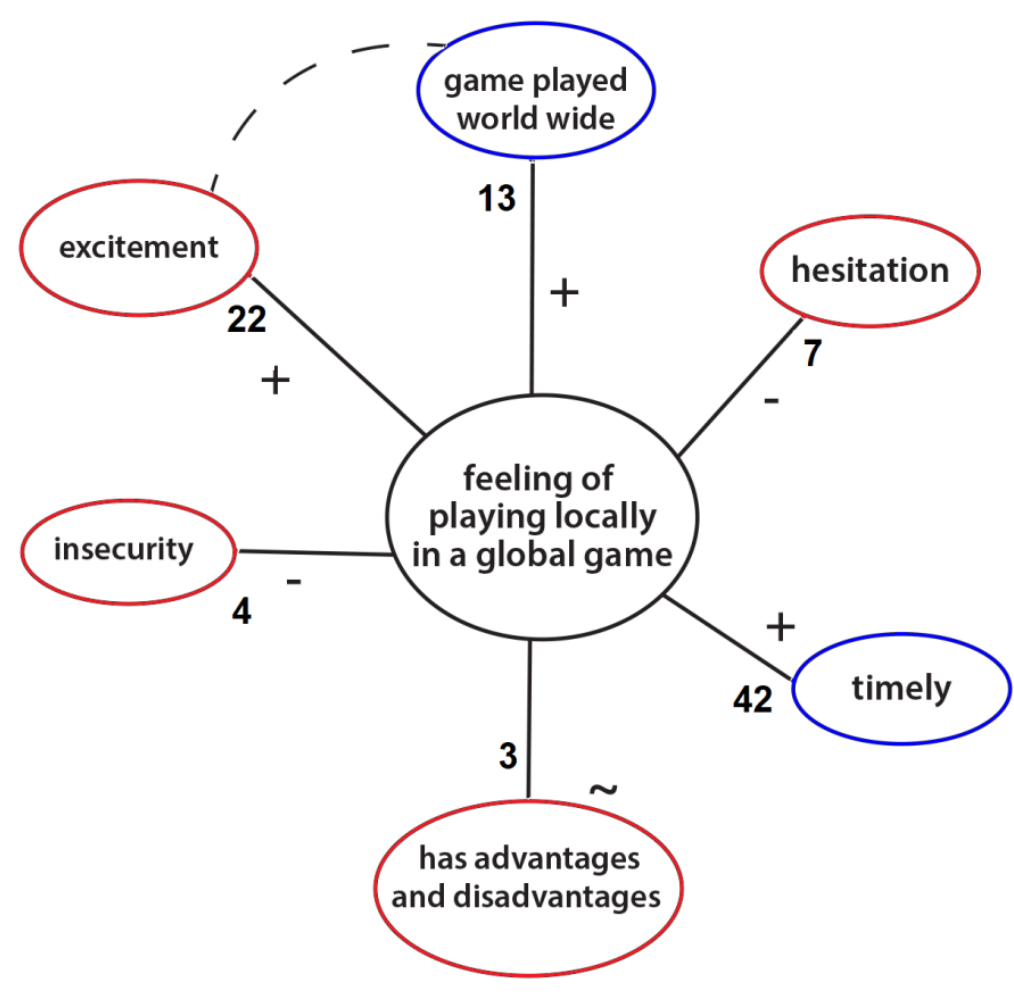

Figure 3. Subthemes with percentages of mentions related to the main thematic "feeling of playing locally in a global game" (question 3). Two subthemes were mentioned more than once (with dotted links). Subthemes with red color relate the user and with blue the game.

iv) $\underline{\text { Idle phases }}$

Initial descriptive statistics showed that $83.33 \%$ of the players rated Ingress as extremely interesting, without boring phases in-between activities, as one activity follows another with specific goals that the player is required to accomplish. Special mention is made of the fields the map shows, as well as the fact that the portals are in real places in the area, such as shops and cultural heritage sites. As for the participants who stated that it has boring intervals, they pointed out as causes the need to walk in order to play the game, long distances among portals, the exposure to weather conditions and the slow transition from one level to another.

In particular, responses to question 4 conclude as follows: The thematic "idle phases" are related to 8 subthemes (figure 4): they may be due to large distances between portals, they are seldom experienced because the game has clear goals at every level, the map of the area provided by the software is helpful, activities run smoothly, it is easy to exit and reenter the game at any time the user wishes, running between levels is relative slow, the software's oral instructions are helpful and the weather conditions affect the play. Of these eight subthemes, five are evaluated positively, two negatively and one both positively and negatively (the weather conditions) and in $1 / 3$ of the cases the same players mentioned at least two subthemes.

All the positive subthemes (clear goals at every level, real map of the area, smoothly running of activities, easy exit and reenter and weather) were mentioned more than once. The subtheme "real map of the area" was mentioned in $31 \%$ of the mentions. Next follows the smooth running of activities with $24 \%$ of mentions, therefore these two 
subthemes account for over $50 \%$ of mentions. The subtheme "real map" was equally emphasized by the age groups 20-35 and 52> with a percentage of $36 \%$ and less by the age group 36-51 with a percentage of $28 \%$.

From the qualitative analysis of the content, two players characteristically responded:

"If it was even a little boring, I would tell you right away and I would not bother a second time. But I liked it that such a real and challenging game has been created, so I tend to deal with it".

"It is boring to walk from one place to another, especially when they are somewhat distanced. Just that. Because otherwise it is a very convincing game".

The mean similarity of the responses between the participants was calculated with the Jaccard similarity index was 0,17 .

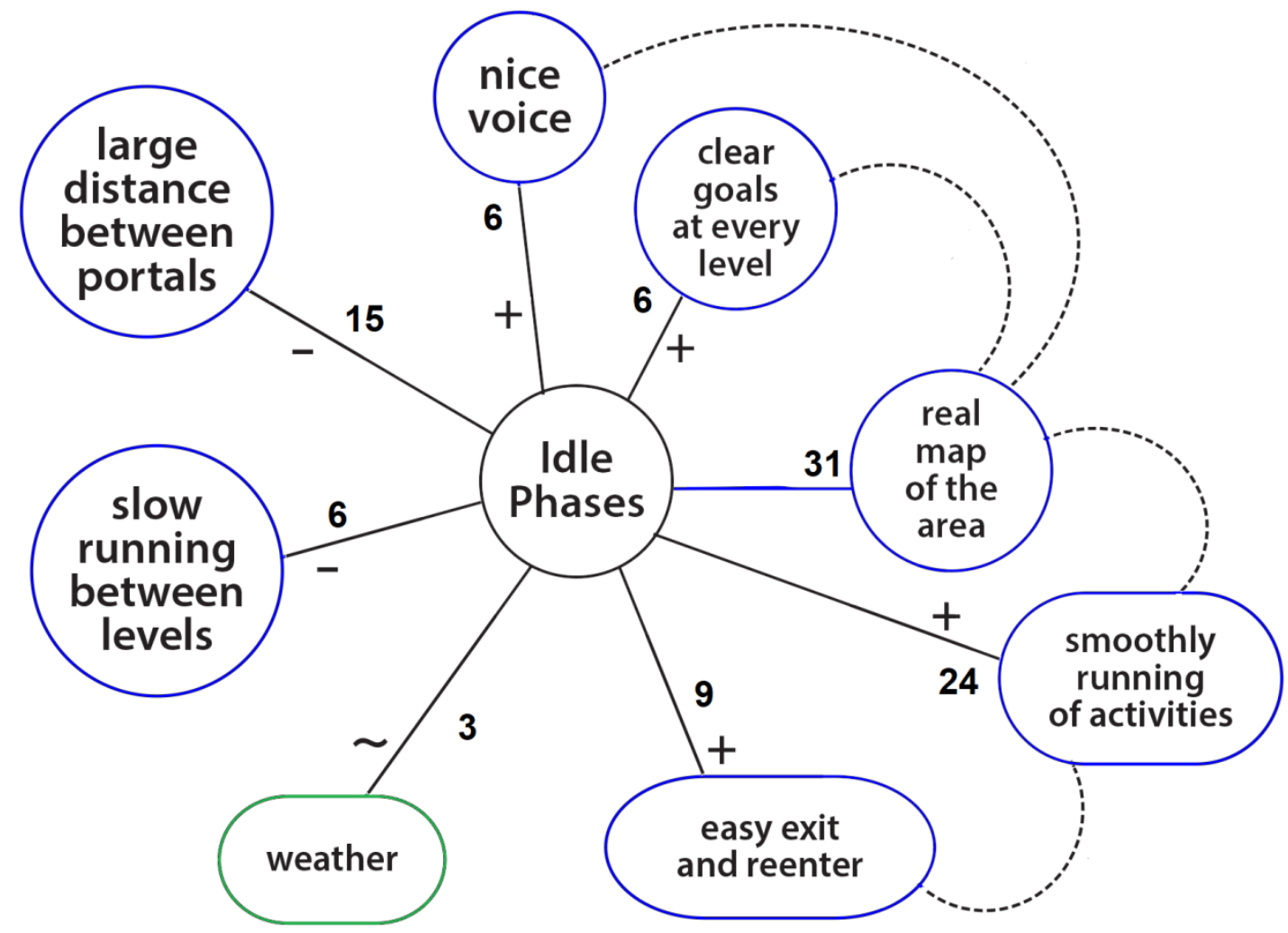

Figure 4. Subthemes (with percentages of mentions) related to the main thematic "idle phases", as derived from the content analysis of the responses to question 4. The subthemes "clear goals at every level", "real map of the area", "smoothly running of activities", "easy exit and reenter" and "weather" were mentioned more than once by the participants who mentioned also the subthemes that are connected with dotted links. Subthemes with blue color relate to the game and green to the environment.

\section{v) Suggested changes to the game}

When asked about the changes proposed to the game by the participants, some of the opinions expressed were that they would add shapes, turn the sound louder, make colors more lively, insert more informative texts, while most participants answered that they would not make any substantial changes to the game. 
The thematic "changes to the game" is related to 9 subthemes; the following (figure 5): more shapes, more intense colors, more texts, louder sounds, not personalized shapes, logo for each group, more portals, fewer symbol and, expectedly, some responded that no changes would be necessary (32\%).

Some characteristic answers are:

“No changes to it. First of all, it's a game and so it's expected to have shapes, and colors and music. And because it is an augmented reality game, the relationship with the natural environment is very welcome. An augmented reality game can not be deprived from shapes and sounds, because it would not be a game after all, and on the other hand, it cannot be full of such, because it would not be "augmented" reality but "virtual" reality instead".

"Yes, much more informative texts about streets, squares, parks, that is, this street is called ... and a few words about the name of the street, below this square is called a square .... a few words about the name of the square and then it should be full of various information. As for the colours, I would make them a little more intense, they look very neutral to me".

The subtheme "no changes" was equally mentioned by the age groups 20-35 and 36-51 (with percentage $44 \%$ ), followed by the age group $52>$ with a percentage of $12 \%$. The mean similarity of the responses between the participants was calculated with the Jaccard index at 0,17 .

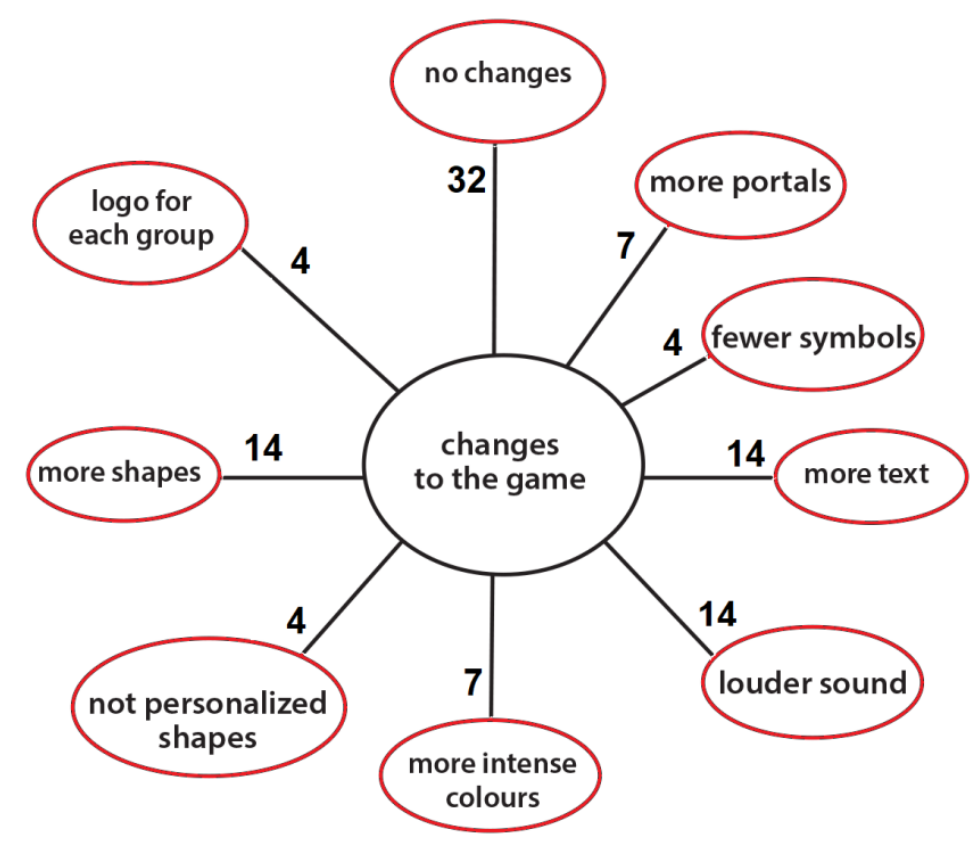

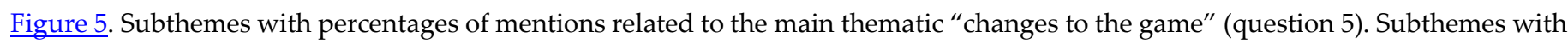
red color relate the user.

From the values of inter-age group indices of similarity $J_{u, v}$, and as concerns question 1 about whether the knowledge of the geography of their area helped the users in the game, the age group 36-51 completely agreed with the group 52> that it is a game fundamentally based on geography, as well as that playing it in an unknown area is a source of extra difficulty. 
With respect to question 2 about the game scenario, the age group 36-51 agrees more with the group of 52>, mainly in the view that it interestingly reflects some of the current debate on the evolution of humanity.

As regards question 3 which deals with how the adult learners felt like when they played locally in a world game, a higher agreement was observed between the age groups 20-35 and 52> primarily in that Ingress is a timely game, and then with balanced feelings of both excitement and insecurity.

In question 4, on whether there are idle phases in the game, the age groups 20-35 and 52> agreed more that the game does not present idle phases for reasons such as that it has a built-in real map, smooth flow of activities and it is easy exit and reenter.

Finally, as relates to question 5 (on whether they had to suggest any changes to the game), the highest agreement was observed between the age groups 20-35 and 52> that they would not make any change to the game.

Hence, in most questions, the higher agreements were observed between the age groups 20-35 and 52> (figure 6). This is somewhat unexpected: in most questions, the lowest agreement is between groups 20-35 and 36-51, meaning the game is perceived differently by people of age 35 or more.

The matrices of the Jaccard similarities in responses for all subthemes for all the age groups per question are given in table 2 and the levels of confidence following test for statistical significance in table 3.

Table 2. Sums of Jaccard similarity indices $J_{u, v}$ (for ages $u$ and $v$ ) per question $Q_{\mathrm{k}}$. for all responses for all subthemes for the three age groups, per question.

\begin{tabular}{|c|c|c|c|}
\hline & & Age groups & \\
\hline $\begin{array}{l}\text { Age groups } \\
\text { and } \\
\text { questions }\end{array}$ & $20-35$ & $36-51$ & $52-67$ \\
\hline \multirow[t]{2}{*}{ 20-35 } & & & \\
\hline & 5.67 & 8.50 & 6.67 \\
\hline $\mathrm{Q}_{1}$ & 17.3 & 15.30 & 13.00 \\
\hline $\mathrm{Q}_{2}$ & 6.00 & 15.33 & 15.83 \\
\hline $\mathrm{Q}_{3}$ & 2.83 & 13.42 & 11.10 \\
\hline $\mathrm{Q}_{4}$ & 6.50 & 20.83 & 5.50 \\
\hline $\mathrm{Q}_{5}$ & & & \\
\hline \multirow[t]{2}{*}{$36-51$} & & & \\
\hline & & 2.00 & 5.00 \\
\hline $\mathrm{Q}_{1}$ & & 4.00 & 8.00 \\
\hline $\mathrm{Q}_{2}$ & - & 11.0 & 21.0 \\
\hline $\mathrm{Q}_{3}$ & & 5.30 & 10.5 \\
\hline $\mathrm{Q}_{4}$ & & 6.83 & 7.00 \\
\hline$Q_{5}$ & & & \\
\hline \multirow[t]{2}{*}{$52-67$} & & & \\
\hline & & & 1.83 \\
\hline $\mathrm{Q}_{1}$ & & & 1.00 \\
\hline $\mathrm{Q}_{2}$ & - & - & 5.67 \\
\hline
\end{tabular}




\begin{tabular}{|l|l|l|l|}
\hline $\mathrm{Q}_{3}$ & & & 4.50 \\
$\mathrm{Q}_{4}$ & & & 2.00 \\
$\mathrm{Q}_{5}$ & & & \\
\hline
\end{tabular}

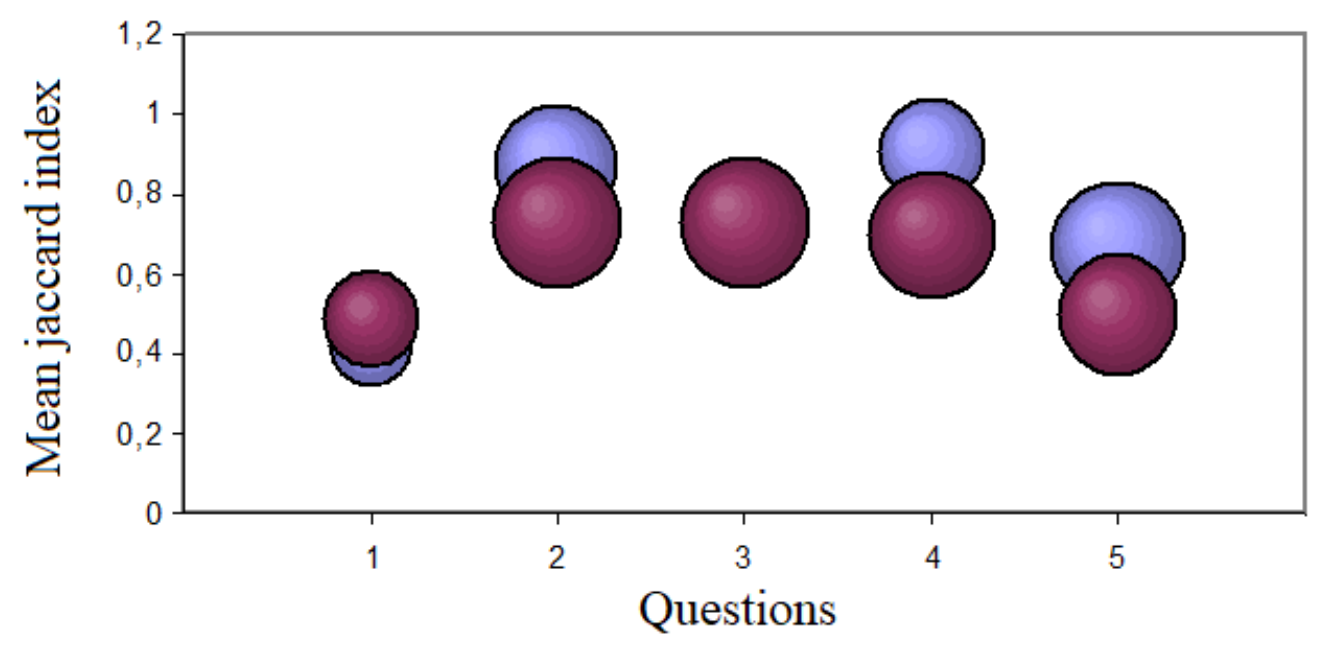

Figure 6. Values of the mean Jaccard index (with their standard deviations) per question for the comparisons between age groups 20-35 and 36-51 (lower row of balls) and 20-35 and >52 (upper row of balls): The age groups 20-35 and >52 have higher means of agreement than the pair of ages 20-35 and 36-51.

Table 3. Level of significance of the values of $J_{u, v}$ for each question.

\begin{tabular}{|l|l|}
\hline & $\begin{array}{l}\text { Interval level of } \\
\text { significance } \alpha\end{array}$ \\
\hline $\mathrm{Q}_{1}$ & $90 \%<\alpha<95 \%$ \\
\hline $\mathrm{Q}_{2}$ & $99 \%<\alpha<99.5 \%$ \\
\hline $\mathrm{Q}_{3}$ & $97.5 \%<\alpha<99 \%$ \\
\hline $\mathrm{Q}_{4}$ & $95 \%<\alpha<97.5 \%$ \\
\hline $\mathrm{Q}_{5}$ & \multicolumn{2}{|c|}{$\alpha>99.9 \%$} \\
\hline
\end{tabular}

\section{Discussion}


Our study revealed that adult learners focus on different issues which are ideally revealed through content analysis ("subthemes"). The theory and practice of adult education have revealed that their responses are, in most cases, more complicated in meanings and attitudes than those of youngsters. This is reflected by the fact that their personal experiences and professional expertise often intermingle with the way they judge anything new they learn. For this reason, content analysis may be more appropriate to discover what they think about the subject they learn.

Content analysis is more complex and complicated than quantitative analysis [30] and there are no clear rules for data analysis with it, as each investigation is unique and the outcomes are determined by the investigator's talents, insights, observational abilities, and style [31]. One of the challenges of content analysis is that it is very flexible, and there is no one-size-fits-all approach. Researchers must determine which combinations are most suitable for their specific problems [32], which makes the research process both difficult and fascinating. This research process has received little attention in the literature of ICTs in education. Backman \& Kyngäs [33] described the beginning of the categorization process as chaotic, since researchers have many apparently unconnected pieces of knowledge to cope with and classify. Another issue is that the content of the narrative is seldom linear, and transcribed interview paragraphs can include elements from multiple categories [34,30]. Reporting and presenting the study's findings can be difficult as well, since the findings are the product of a multi-phase process. Some aspects of this process can be described in great detail, but others, such as the researcher's own behavior and insights, may be difficult to express [33].

But our study has nevertheless has had some limitations. One is the small number of game players, another is that it is possible that some of the findings of this study might be biased by particular geographical settings (i.e. different cities, cityscapes within the same city), or by the participants' particular demographics and thus further research under different conditions and participants might be needed. Also, with alternative classifications of the three age categories, different results might be derived, but this particular classification in three classes has however revealed some similarities and differences among age groups. However, content analysis, as a research methodology, is shown to offer new perspectives, improving a researcher's comprehension or advises realistic behaviour and is therefore an appropriate method for analyzing data particularly those derived from research in adult education [21]. In this paper, content analysis was ideally combined with Jaccard similarity index, because it was applied to record agreements and disagreements between subthemes and in this way allowed us to analyze qualitative data (i.e. the subthemes) quantitatively. Furthermore, the combination of content analysis and Jaccard similarity index can be used in similar studies also (i.e. for analyzing texts relating to user interface and qualitative software evaluation). Until now, quantitative content analysis was used either by measuring the frequencies of words in a text, or qualitatively only (exploring meanings and semantics).

As regards the game itself, the subtheme "knowledge of geography facilitates playing the game better" seems to occupy a central position among the opinions expressed in answering question 1. Moore [35] observed that players of Ingress sought to assert and protect territories within physical environments by generating control fields, since players who use public landmarks as "portals" hack and protect these landmarks in order to gain control of specific areas. Ingress, like other types of urban mobile gaming, allows players to interact with both their mobile device and the urban environment at the same time. Pervasive games have historically been used to investigate such activities as an extension of the gaming world into everyday spaces [36, 37]. In contrast, urban play has been debated as a natural part of daily life, with parallels drawn between historically situated urban mobility activities such as the "flâneurie" [38]. In the case of urban mobile games like Ingress, play is influenced by sociocultural circumstances prevailing in an area, while at the same time, the play generates a new, unique perception of urban environments [35] that is based on one of AR's most characteristic feelings, the "immersion". According to Gong et al. [39], location-based mobile games 
are gradually turning "serious" ordinary space into playful space, thereby blurring the lines between play and everyday life. The use of mobile devices and the physical movement of players in space has increased the importance of the social construction of space. In addition, the game reveals new information about people's mobility habits.

From the responses to the question concerning the scenario of Ingress, it is noticeable that the subtheme highlighting the fact that the game convincingly relates to the evolution of humanity accounted for $41 \%$ of the respondents and this points to the a much-discussed and timely issue regarding socialization through MAR (Mobile Augmented Reality) games. It is widely recognized that location-based AR is more suitable for building scenarios and for promoting collaboration. Moreover, naturalistic approaches applied to location-based MAR are suitable for designing multidisciplinary applications, can be used for training and have the potential to be designed so as to account for locality and context [40].

When participants were asked how they felt while playing locally in a global game, a $22 \%$ of them expressed enthusiasm that it is a game adapted to our daily life, which mostly follows the ubiquitous "glocalization" patterns of contemporary life. However, due to the real-world nature of Ingress, Windleharth [41] stated that the "Ingress Communities of Practice" (CoPs) face unique challenges, such as risks to physical safety in order to achieve game goals, "spying" (with attempts to gather information from in-game and out-of-game systems), while monitoring real-world locations and behaviors, risking real-world identity exposure, along with a range of other issues (such concerns were also mentioned by some $11 \%$ of the respondents in our study). The Ingress CoPs have developed specific practices to solve problems that blur the line between digital and real-world gaming, encouraging players to self-police and change their actions to suit group norms. The vast majority of responses were that the game is very interesting, that its activities flow smoothly and that there are clear goals at every level. Those players who stated that Ingress has idle phases mentioned the need to walk long distances in-between portals, the fact that the levels proceed slowly and the highlighted the weather factor (which may impose restrictions to play).

Previous studies $[42,43,44]$ showed that younger adults (18-35 years) are said to be more familiar with videogames than older adults (67 years and older). However, Madrigal-Pana et al. [12] agree that game exposure and practice rather than age, could be to blame for any negative attitudes towards games. Indeed, new research shows that once older adults grasp and play videogames, their negative attitudes gradually fade away [45, 46]. This coincides with the findings of our research with Ingress from which a positive attitude to Ingress was revealed, even by adult users of the age group 52>. This backs up the idea that, at least in part, questions about such games stem from a lack of experience with the medium. This is also supported by research from Przybylski [47], which found a connection between negative attitudes toward video games and generational issues.

\section{Conclusions}

This study reveals that, so long as the scenario of a MAR may appeal to adult users, the game can very well be approached and played by adults of various ages and educational backgrounds. Location-based MAR games offer the additional advantage to adult users that they combine physical activity with the excitement offered by AR technology.

Particularly as concerns the game Ingress, we can conclude that regarding the playing of Ingress by adult users who play it for the first time, those over 36 years old focused on the fact that it is primarily a geographical game and its scenario reflects interesting discussions about the evolution of humanity. Next, whether the game is boring and how they feel playing locally in a world game and with respect to any changes they would suggest, the highest agreement among participants' views was observed between the age groups 20-35 and $>52$, commenting that the game does not have idle phases, that it combines excitement with insecurity, about playing in their country within a game of planetary proportions and that they would not suggest any notable change in the game's design or settings. 
Also, methodologically, it is shown that content analysis presents the researcher with several advantages: texts derived from interviews and/or answers to open questions of educational research can be analyzed both qualitatively and quantitatively with Jaccard indices. The method proposed here shows how, after subthemes were identified from within the typical content analysis methods, may subsequently be analyzed by means of Jaccard indices in order to derive assessments of agreement of the participants' responses.

Author Contributions: For research articles with several authors, a short paragraph specifying their individual contributions must be provided. The following statements should be used "Conceptualization, Konstantina Sdravopoulou; methodology, Konstantina Sdravopoulou; formal analysis, Konstantina Sdravopoulou; investigation, Konstantina Sdravopoulou; data curation, Konstantina Sdravopoulou; writing-original draft preparation, Konstantina Sdravopoulou; writing — review and editing, Konstantina Sdravopoulou; visualization, Konstantina Sdravopoulou; supervision Juan Manuel Muñoz González, María Dolores Hidalgo-Ariza; project administration, Konstantina SdravopoulouX.X.;. All authors have read and agreed to the published version of the manuscript."Please turn to the CRediT taxonomy for the term explanation. Authorship must be limited to those who have contributed substantially to the work reported.

Funding: This research received no external funding

Institutional Review Board Statement: Ethical review and approval were waived for this study, due to the fact that all participants were adults and participated by their own will.

Informed Consent Statement: Informed consent was obtained from all subjects involved in the study.

Conflicts of Interest: The authors declare no conflict of interest.

\section{References}

1. Salehan, M., \& Negahban, A. (2013). Social networking on smartphones: When mobile phones become addictive. Computers in human behavior, 29(6), 2632-2639.

2. Fernández-Enríquez, R., \& Delgado-Martín, L. (2020). Augmented Reality as a Didactic Resource for Teaching Mathematics. Applied Sciences, 10(7), 2560.

3. Cabero-Almenara, J., \& Roig-Vila, R. (2019). The motivation of technological scenarios in augmented reality (AR): Results of different experiments. Applied Sciences, 9(14), 2907.

4. Sepasgozar, S. M. (2020). Digital twin and web-based virtual gaming technologies for online education: A case of construction management and engineering. Applied Sciences, 10(13), 4678.

5. Javornik, A. (2016). Augmented reality: Research agenda for studying the impact of its media characteristics on consumer behaviour. Journal of Retailing and Consumer Services, 30, 252-261.

6. Craig, A. B. (2013). Understanding augmented reality: Concepts and applications. Newnes.

7. Rauschnabel, P. A., Rossmann, A., \& tom Dieck, M. C. (2017). An adoption framework for mobile augmented reality games: The case of Pokémon Go. Computers in Human Behavior, 76, 276-286.

8. Scholz, J., \& Smith, A. N. (2016). Augmented reality: Designing immersive experiences that maximize consumer engagement. Business Horizons, 59(2), 149-161.

9. tom Dieck, M. C., Jung, T., \& Han, D. I. (2016). Mapping requirements for the wearable smart glasses augmented reality museum application. Journal of Hospitality and Tourism Technology.

10. Lee, M. H., \& Tsai, C. C. (2010). Exploring teachers' perceived self efficacy and technological pedagogical content knowledge with respect to educational use of the World Wide Web. Instructional Science, 38(1), 1-21.

11. Schade, S., Mahoney, J., Spotts, A., Greenauer, N., \& Veerabhadrappa, P. (2020). Pokémon go did not increase step count or distance travelled among college students. Human Movement, 21(2), 64-70.

12. Madrigal-Pana, J., Gómez-Figueroa, J., \& Moncada-Jiménez, J. (2019). Adult perception toward videogames and physical activity using Pokémon Go. Games for health journal, 8(3), 227-235. 
13. Ma, B. D., Ng, S. L., Schwanen, T., Zacharias, J., Zhou, M., Kawachi, I., \& Sun, G. (2018). Pokémon GO and physical activity in Asia: multilevel study. Journal of medical Internet research, 20(6), e217.

14. Finco, M. D., Rocha, R. S., Fão, R. W., \& Santos, F. (2017, October). Pokémon GO: A healthy game for all. In European Conference on Games Based Learning (pp. 165-172). Academic Conferences International Limited.

15. Courau, S. (2000). The basic "tools" of the adult educator. Athens: Metechmio.

16. Kelly, G. A. (1955). The psychology of personal constructs Norton. New York.

17. Hamari, J., Hanner, N., \& Koivisto, J. (2017). Service quality explains why people use freemium services but not if they go premium: An empirical study in free-to-play games. International Journal of Information Management, 37(1), $1449-1459$.

18. Lee, C. H., Chiang, H. S., \& Hsiao, K. L. (2018). What drives stickiness in location-based AR games? An examination of flow and satisfaction. Telematics and Informatics, 35(7), 1958-1970.

19. Lee, J. H., Keating, S. A., \& Windleharth, T. W. (2017). Challenges in Preserving Augmented Reality Games: A Case Study of Ingress and Pokémon GO. In iPRES.

20. Cohen, L., Manion, L. \& Morrison, K. (2008). Educational research methodology. Athens: Metechmio.

21. Krippendorff, K. (2004). Reliability in content analysis: Some common misconceptions and recommendations. Human communication research, 30(3), 411-433.

22. Stefanovič, P., Kurasova, O., \& Štrimaitis, R. (2019). The n-grams based text similarity detection approach using self-organizing maps and similarity measures. Applied sciences, 9(9), 1870.

23. Jaccard, P. (1901). Distribution de la flore alpine dans le Bassin des Drouces et dans quelques regions voisines. Bulletin de la Société Vaudoise des Sciences Naturelles, 37(140), 241-272.

24. Hamers, L. (1989). Similarity measures in scientometric research: The Jaccard index versus Salton's cosine formula. Information Processing and Management, 25(3), 315-18.

25. Leydesdorff, L. (2008). On the normalization and visualization of author co-citation data: Salton's Cosine versus the Jaccard index. Journal of the American Society for Information Science and Technology, 59(1), 77-85.

26. Egghe, L. (2009). New relations between similarity measures for vectors based on vector norms. Journal of the American Society for Information Science and Technology, 60(2), 232-239.

27. Leydesdorff, L., Kogler, D. F., \& Yan, B. (2017). Mapping patent classifications: portfolio and statistical analysis, and the comparison of strengths and weaknesses. Scientometrics, 112(3), 1573-1591.

28. Fried, E. I. (2017). The 52 symptoms of major depression: Lack of content overlap among seven common depression scales. Journal of affective disorders, 208, 191-197.

29. Verma, V., \& Aggarwal, R. K. (2020). A comparative analysis of similarity measures akin to the Jaccard index in collaborative recommendations: empirical and theoretical perspective. Social Network Analysis and Mining, 10, 1-16.

30. Polit, D. F., \& Beck, C. T. (2004). Nursing research: Principles and methods. Lippincott Williams \& Wilkins.

31. Hoskins, C. N., \& Mariano, C. (2004). Research in nursing and health: Understanding and using quantitative and qualitative methods (Vol. 23). Springer publishing company.

32. Weber, R. P. (1990). Basic content analysis (No. 49). Sage.

33. Backman, K., \& Kyngäs, H. (1998). Challenges of the grounded theory approach to a novice researcher. Hoitotiede, 10(5), 263-270.

34. Dey, I. (2003). Qualitative data analysis: A user friendly guide for social scientists. Routledge.

35. Moore, K. (2015). A situated approach to urban play: The role of local knowledge in playing Ingress. In The refereed conference proceedings of the annual conference of the digital games research association of Australia.

36. Montola, M., Stenros, J., \& Waern, A. (2009). Pervasive games: theory and design. CRC Press.

37. Nieuwdorp, E. (2007). The pervasive discourse: an analysis. Computers in Entertainment (CIE), 5(2), 13. 
38. Hjorth, L. (2011). Games and gaming: An introduction to new media. Berg.

39. Gong, H., Hassink, R., \& Maus, G. (2017). What does Pokémon Go teach us about geography?. Geographica Helvetica, 72(2), 227-230.

40. Sdravopoulou, K., Castillo, J.J.G., \& González, J.M.M. (2021). Naturalistic approaches applied to AR technology: an evaluation. Education and Information Technologies, 26(1), 683-697.

41. Windleharth, T. W. (2020). Identity, Safety, and Information Management within Communities of Practice in Location-based Augmented Reality Games: A Case Study of Ingress.

42. Malik, A., Hiekkanen, K., Dhir, A., \& Nieminen, M. (2016). Impact of privacy, trust and user activity on intentions to share Facebook photos. Journal of Information, Communication and Ethics in Society.

43. Malik, A., Hiekkanen, K., Hussain, Z., Hamari, J., \& Johri, A. (2019). How players across gender and age experience Pokémon Go?. Universal Access in the Information Society, 1-14.

44. Taddicken, M. (2014). The 'privacy paradox'in the social web: The impact of privacy concerns, individual characteristics, and the perceived social relevance on different forms of self-disclosure. Journal of Computer-Mediated Communication, 19(2), 248-273.

45. Ferguson, C. J., \& Donnellan, M. B. (2017). Are associations between "sexist" video games and decreased empathy toward women robust? A reanalysis of Gabbiadini et al. 2016. Journal of youth and adolescence, 46(12), 2446-2459.

46. Ivory, J. D., \& Kalyanaraman, S. (2009). Video games make people violent -Well, maybe not that game: Effects of content and person abstraction on perceptions of violent video games' effects and support of censorship. Communication Reports, 22(1), 1-12.

47. Przybylski, A. K. (2014). Electronic gaming and psychosocial adjustment. Pediatrics, 134(3), 716-722. 